\title{
Constructivism, the So-Called Semantic Learning Theories, and Situated Cognition versus the Psychological Learning Theories
}

\author{
Juan José Aparicio ${ }^{1}$ and María Rodríguez Moneo ${ }^{2}$ \\ ${ }^{1}$ Universidad Complutense de Madrid \\ ${ }^{2}$ Universidad Autónoma de Madrid
}

\begin{abstract}
In this paper, the perspective of situated cognition, which gave rise both to the pragmatic theories and the so-called semantic theories of learning and has probably become the most representative standpoint of constructivism, is examined. We consider the claim of situated cognition to provide alternative explanations of the learning phenomenon to those of psychology and, especially, to those of the symbolic perspective, currently predominant in cognitive psychology. The level of analysis of situated cognition (i.e., global interactive systems) is considered an inappropriate approach to the problem of learning. From our analysis, it is concluded that the pragmatic theories and the so-called semantic theories of learning which originated in situated cognition can hardly be considered alternatives to the psychological learning theories, and they are unlikely to add anything of interest to the learning theory or to contribute to the improvement of our knowledge about the learning phenomenon.

Keywords: constructivism, cognitive theories of learning, symbolic theories, pragmatic theories, situated cognition, situated learning
\end{abstract}

\begin{abstract}
En este artículo se examina el punto de vista de la cognición situada, que da origen tanto a las teorías pragmáticas como a las llamadas teorías semánticas del aprendizaje y que se ha convertido, probablemente, en la posición más representativa del constructivismo. Nuestro análisis intenta profundizar en la pretensión de la cognición situada de proporcionar explicaciones al fenómeno del aprendizaje alternativas a las de la psicología y, especialmente, a las que se dan desde una perspectiva simbólica, dominante en la psicología cognitiva. Se constata, también, que el nivel de análisis de la cognición situada, el de los sistemas globales interactivos, es inapropiado para abordar el problema del aprendizaje. De nuestro análisis se desprende que las teorías pragmáticas y las llamadas teorías semánticas del aprendizaje derivadas de la cognición situada difícilmente pueden constituirse en una alternativa a las teorías del aprendizaje desarrolladas en la psicología e, incluso, se pone en duda que puedan aportar algo de interés a la teoría del aprendizaje y contribuir, así, al desarrollo de nuestros conocimientos sobre el fenómeno del aprendizaje.

Palabras clave: constructivismo, teorías cognitivas del aprendizaje, teorías simbólicas, teorías pragmáticas, cognición situada, aprendizaje situado
\end{abstract}

Correspondence concerning this article should be addressed to Juan José Aparicio, Departamento de Psicología Básica I, Universidad Complutense de Madrid, Facultad de Psicología, Campus de Somosaguas, 28223 Madrid (Spain). Phone: 91-3943149 E-mail: jjapar@psi.ucm.es

Translation: Virginia Navascués Howard 
Ever since the eighties, a current of thought about the dynamics of the acquisition and use of knowledge, which has been called situated cognition, has gained predominance in the field of philosophy, and particularly in philosophy of education. An approach to learning developed from this epistemological current, which is usually considered pragmatic, and which is known as situated learning. For reasons that will be understood later on in this paper, this viewpoint has even allowed some authors to defend what they call semantic learning theories and to set them up against the psychology viewpoints, which they classify as being unsemantic. All these supposed learning theories, whether they are called pragmatic, situated, or semantic, are characterized by their emphasis on the importance of the interactive and psychosocial situations in which learning takes place - which, as will be seen, winds up ignoring the fact that learning is an individual phenomenon. The immediate result is that the equation of learning and acquisition of knowledge becomes blurry. Therefore, some proponents of situated cognition offer explanations about learning that they consider alternatives to the clearly cognitive viewpoint currently predominant in psychology, in which learning is clearly identified with acquisition of knowledge. The aim of this article is to argue against this vindication of situated cognition to set itself up as an alternative to psychology and to show how its contribution to the progress of the learning theories is highly improbable due to the deficiencies of its analysis.

The viewpoint of situated cognition has been incorporated, under the label of social constructivism, into a whole blend of ideas, which in the field of education are grouped under the global term of constructivism ${ }^{1}$, and which include, among others, Piaget's (1970, 1970/1971) genetic epistemology and some notions from cognitive psychology. Piaget's theory has sometimes been presented as an alternative to cognitive psychology and, more specifically, to symbolic theories (see, for example, Pascual-Leone, 1980). However, as situated cognition is probably the most original contribution within what some writers consider constructivism, in this article, we reflect on situated cognition in particular and not constructivism in general. Had we chosen the second alternative, it would have been necessary to address the analysis of different and sometimes contradictory viewpoints, which would probably have led to some confusion ${ }^{2}$.

On the other hand, no matter what constructivism is, authors have sometimes attempted to set up supposed constructivist learning theories against so-called informationprocessing theories, ignoring the fact that the label information-processing theories seems to include everything in psychology that is known about learning. It is therefore important to clarify what these constructivist theories claim as their own and which might be important enough to become an antagonist or alternative standpoint to the explanations of learning provided by psychology. Again, after a careful scrutiny of the literature on constructivism, it seems obvious that, except for some excesses that do not deserve further attention, the only approach that could disagree with the psychological explanations is precisely the approach of situated cognition. This is another reason for undertaking a detailed examination of the possible contributions of situated cognition: to clarify whether constructivism in general and situated cognition in particular are really an alternative standpoint to psychology.

We would like to note that not all the constructivist learning theories from the educational field are presented as always being incompatible with cognitive psychology. But that is probably worse because then, as stated by Anderson, Reder, and Simon (1996, p. 5), "some educational opinion, including opinion that is quite contrary to the body of empirical evidence available on these matters, is presented as deriving from cognitive psychology." Therefore, it is preferable for this kind of doctrine to declare itself an alternative to cognitive psychology so that some element that might contribute to the progress of learning theories could be detected in this declaration of incompatibility.

\section{The Nature of Situated Cognition}

Situated cognition starts out from the overvalued fact that knowledge processes depend on context, more specifically, on the interaction between the individual and the context. This overvaluation turns both the context and the interactions taking place in it into determining factors and, sometimes, into unique factors to explain the dynamic of these processes. Thus, the phenomenon of learning could only be understood within the specific contexts in which it is produced, so that, according to this viewpoint, there can hardly be transfer from one context to another. The immediate consequence is that, for situated cognition, as previous knowledge-which mobilizes an individual to cope with a new experience-is the result of prior experiences

\footnotetext{
1 Although some authors treat constructivism and situated cognition like two independent movements (see, for example, Seel, 2001), we have opted, like many other authors and for efficacy, for classifying situated cognition within the constructivist movement, despite - as mentioned in Footnote 2-it could be classified in what some authors understand as constructivism in a separate movement.

2 Steffe and Gale (1995) differentiated up to six different paradigms that coexist within constructivism: social constructivism, radical constructivism, social constructionism, information-processing constructivism, cybernetic systems constructivism, and the sociocultural approach of mediated action. Some of these so-called paradigms are actually variants of situated cognition.
} 
and was therefore generated in other contexts, is ultimately somewhat irrelevant to explain the formation of new functional units of knowledge, which are developed from that same experience and which, when all is said and done, are the result of learning. Therefore, people's available knowledge is, at any rate, not as important to explain learning processes as their interaction with their environment.

As there is some consensus in psychology, in the sense that the representation of knowledge is of a symbolic nature, the underestimation of the role of "knowledge in the mind" involves the rejection of the symbolic theories, because, by means of these theories, researchers try to explain how the available knowledge in peoples' minds determines the mental operations they perform. From the viewpoint of artificial intelligence, for example, this implies that, according to situated cognition, the traditional approach — which assumes that the reuse of the existing symbolic descriptions is the main tool on which intelligent activities are based-should be modified. Seen from another point of view, according to some versions of situated cognition, knowledge accumulated in an intelligent system, such as, for example, the human mind, does not determine the nature of the operations that the system performs, because the contexts in which the knowledge is generated are unrepeatable, so that knowledge originating in one context is not usable in another. Thus, the concept of representation, so central to cognitive psychology, loses its power and, according to situated cognition, research should focus not so much on describing knowledge in the mind, but rather on the nature of the system's interaction with the environment, starting with the system's goals, which, in turn, are generated in that environment. This way leads to extremes that are impossible to accept, according to which knowledge is not "inside an individual's skin" (Agre \& Chapman, 1987; Lave, 1988; Suchman, 1987) but instead, outside, as a result of the person's interaction with the environment.

Situated cognition has inherited a broader, functionalist and pragmatist, philosophical trend regarding human action. From this trend, people and their physical and social environments are envisaged as a function of the contribution of both environment and persons to an activity that takes place conjointly, and not as separate entities that can be independently described. This interaction leads to synchronization between persons and their environment that is not based on possible comparisons between the world and subjects' internal representations, but that implies a mutual dynamic modification. It is just this interactive (Bickhard, 1992), relational (Lave \& Wenger, 1991), or dialectic (Clancey, 1992) conception that has comprised the nucleus of the work carried out in situated cognition and that gives rise to the pragmatic theories of situated learning.

One of the consequences of this standpoint is the difference of perspectives between cognitive psychology and situated cognition. Whereas cognitive psychology attempts to explain processes and structures at the individual level, situated cognition focuses on global interactive systems, so that, at the individual level, their analyses only lead to the description of the trajectories resulting from the individual's participation in certain environments. For situated cognition, people's knowledge is not only in their headsif it can be said to be there-but instead it consists of the way that people interact with other people and with the situations they cope with.

In turn, this difference leads to another difference in the approach. Psychology tends to carry out molecular analyses in order to understand how the more elemental processes make sense and are the foundation for more complex processes. On the other hand, situated cognition tends to perform molar analyses, attempting to deal with problems directly, in all their complexity. For situated cognition, people's knowledge about the world is too extensive and complex to be identified and manipulated with the correct amount of detail. Furthermore, according to situated cognition, the world is such a complicated and changing place that people can hardly deal with it using previously established mental representations, when it is precisely the study of the dynamic of mental representations what allows one to carry out analyses at a molecular level.

For situated cognition, it is simply impossible to observe all the relevant aspects of cognition in depth. It is like going back to the fifties, when researchers were arguing about the viability of the scientific study of the mind, a discussion that was sidestepped by the progressive consolidation of cognitive psychology. From our viewpoint, we would like to note that, in some cases, the insufficient development of psychology has certainly sometimes caused some important problems to escape molecular analysis. However, as stated by Baddeley (1976) with regard to psychology of memory, to adopt a molar o globalizing approach to phenomena that are difficult to analyze molecularly is often just a way of running away which involves the risk of making the very problems it tries to analyze unmanageable.

In an effort to synthesize and to limit our study to learning-related topics, one could say that, apart from the general aim of setting itself up as an alternative to psychology, the theoretical viewpoints adopted by situated cognition are important for two reasons. On the one hand, because they point to a problem, no doubt complex, about how learning is the result of the interaction of people with their environment, either social or physical. On the other hand, in much more applied way, because the proposals of situated cognition have been expressed in some learning methods of the teaching field.

With regard to the first point, we first should determine exactly what this kind of viewpoint really contributes to our understanding of the phenomenon of learning. This is not a simple question because, given the fields of knowledge where situated cognition originated - basically philosophy and social sciences-its statements lack the rigor of other domains (such as that of psychology, where theories are 
generally formulated with enough precision to be confirmed by scientific methods such as the experimental method) to offer some guarantee that they are really contributing to the progress of our knowledge. In fact, as will be seen below, both the research methods of situated cognition and the conceptual frameworks it deals with derive from fields such as philosophy, ethnography, discourse analysis, symbolic interactionism, or the sociocultural theory and therefore, it is difficult to elaborate experimentally contrastable theories. Consequently, and in a first approach, we can expect little from the contribution of the analyses of situated cognition to the progress of the theories of learning.

With regard to the second point of the teaching methods, situated cognition is decidedly education-oriented, so that its strength consists of proving the efficacy of its analyses in the application to teaching situations. However, it must be acknowledged that the issue of the teaching methods transcends mere applied interest. The reason is that research on the acquisition of knowledge merges with research on the technologies that support and extend human cognitive processing (Hmelo \& Narayan, 1995). However, for this type of research to bear fruit, it must be based on conceptual frameworks that are scientifically accessible, so that, once again at this point, an effort must be made to clarify the proposals of situated cognition.

In order to fulfill this goal of clarifying the viewpoints of situated cognition, we decided to go back to its origins and foundations. By means of this strategy, a more detailed dissection of the arguments of this current of thought can be made, so as to analyze the nature of the possible contributions of situated cognition to our conceptions of learning.

\section{The Sources of Situated Cognition}

The ideas that merge and give essence to situated cognition have very diverse origins, although the philosophic notion of transactionalism is probably the driving notion on which the entire conceptual body rests. Other ideas have joined this notion, from different fields that, for some reason or another, were present in education. At this point, we would like to point out that situated cognition did not originate within psychology, but rather with regard to the problems of education and other social research fields. Therefore, it cannot be analyzed within the context of the progress of the conceptions of learning in psychology. So, in order to unravel all this mixture of ideas that merge in situated cognition, we are going to group the sources of influence into three large blocks: philosophy, Vigotski's (1978) sociocultural theory, and ethnography. Although in an exhaustive analysis, one would have to also consider other influences such as discourse analysis of linguistics, or Gibson's (1979) ecological theory of perception. We consider the contribution of these fields to be minor or, to a great extent, coinciding with the former; hence, they are not taken into account.

\section{Philosophy}

The main ideas that nourish situated cognition are probably to be found in philosophy. To sum up, these ideas could be classified into three groups, numbered by order of importance: first, Dewey's (Dewey, 1942; Dewey \& Bentley, 1949) transactionalism; second, Ryle's (1949) distinction between knowing what and knowing how; and third, the digression about the semantic and the syntactic, originating in Searle's (1980, 1983, 1984) work.

Regarding the first group is Dewey (1929, 1942), a functionalist philosopher who, along with his master, Peirce, assigned himself the role of founder of pragmatism, and who had an instrumentalist conception of knowledge, in the sense that he conceived ideas as tools used by people to solve problems encountered in their interaction with the environment. He even went into the field of psychology of his times, dominated by behaviorism, criticizing the notion of the reflex arc. For Dewey, whom some consider a "social behaviorist," the reflex arc should be understood linearly and, in consonance with his ideas, although not very successfully, he proposed a circular reflex arc that would better reflect the interaction of organisms with their environment (Dewey, 1896).

He coined the conceptual framework of transactionalism (Dewey \& Bentley, 1949) to address a whole series of phenomena of interaction between the individual and the environment, among which those of an educational nature and, therefore, concerning learning, are noteworthy. Transactionalism, which is the key concept both in situated cognition and in what has been called social constructivism and social constructionism, is based on a metaphor of an economic transaction. When a piece of merchandise is sold, from the viewpoint of the seller (or from that of the buyer when something is bought), there is no established price, but instead the price is fixed in the course of a negotiation. That is, the context in which factors such as the buyer's need to buy or the seller's need to sell, and the scarcity or abundance of the product merge and lead to fixing a price. For example, from the buyer's viewpoint, some changes are produced both in the individual and the environment, which, in this case, mainly comprises the seller. If we translate this analysis into learning, then learning does not start from a fixed representation, but, just as the price is generated as a result of a negotiation, a functional unit is generated which is the result of the interaction between the individual and the environment, and which comprises the content of what is learned. In this sense, certain changes take place as a result of the interaction: in the learner, the effects of the acquisition, and in the learner's social environment, the effects of participation.

This explanation, which smacks of commercial matters, leads to the so-called pragmatic learning theories, among which situated learning is the most representative. The important point is that this view points to some issues that have become more problematic in the last few years. 
First, it should be acknowledged that learning processes are influenced by the context in which learning occurs and, consequently, it should be conceded that people's mental activity must be contemplated in relation with the problems of their environment, which is mainly of a social nature. However, as will be seen below, it is not clear whether the virtue of transactionalism consists of merely limiting itself to indicating the problem or somehow contributing to its solution. However, psychology has made considerable progress in this direction, both in the specific territory and in what could be considered a more general one. As to the specific, because ever since the work of Newell and Simon (1972), carried on by Anderson (1976) or Rosenbloom and Newell (1986), among many others, the dynamic of knowledge has been seen to be at the service of problemsolving behavior and can therefore only be understood, in a sense, within the framework of the problems presented by the environment. As to the more general sphere, because also in psychology, a research program has begun, embarking on studies at a rational level of analysis to attempt to show how the environment sets up the type of mental activity that people carry out (see, for example, Anderson, 1990, 1991).

Second, the idea that learning only occurs naturally within the framework of social interaction has led to what some authors have called psychosocial learning theories. The problem with these theories is that their emphasis on the social processes that take place in group interaction situations leads them to neglect the individual learning mechanisms that take place in these same interactive situations, so that ultimately, individual learning is ignored. The undesirable result of this state of things is that these psychosocial theories do not show us how people learn. The only consideration that links psychology to this type of theories is of a motivational nature. As has been repeatedly demonstrated, in some circumstances, people seem more motivated to learn in interactive situations than in individual learning situations but it is not possible to know how they learn as a result of these theories. Also, while not forgetting that these analyses are clearly incomplete from the viewpoint of motivation, the immediate consequence is that the problem of learning is reduced to the motivation to learn. Obviously, in order to reduce learning to a purely motivational issue, one only has to observe the product of learning and discard the processes. In favorable motivational situations, such as learning in interactive groups, the product must be quantitatively and qualitatively better. Although the processes that take place in the group are usually described, the processes by which group members learn are not clarified. Ultimately, these psychosocial theories are a return to faroff and completely outdated periods, because they adopt a viewpoint like that of the former behaviorists, who insisted on the need to study the changes in the results of learning but ignored the processes by which these changes took place. In the old times, this attitude could be justified because researchers did not have the pertinent intellectual and methodological instruments. Nowadays, however, this kind of neglect is only justifiable in people who are not familiar with the field of learning.

Third, and regarding the above, the concept of transactionalism has, more or less aptly, been used to describe the mechanisms by which social and cultural changes take place and to attempt to understand how individuals contribute to social change. Unfortunately, this natural ranking of transactionalism within "social issues" and its subsequent involvement in "individual issues" has created some confusion between what could be called "social learning" and what in psychology is understood as learning, which is essentially individual.

Fourth, it has also been used to explain that meaning is not fixed, but the result of a negotiation that takes place within an interactive framework. But transactionalism also runs into problems here, basically because its pronounced tendency towards the sense sometimes obscures Frege's ${ }^{3}$ distinction between sense and reference (Frege, 1892). And, primarily, it precludes the analysis of the problem of the relations between sense and meaning.

Finally, from transactionalism, an attempt has been made to build a global theory about the sense of human action, whose evaluation exceeds the limitations of this article. However, when analyzing the sense of human action at a global level suitable for philosophy, the individual's psychological processes tend to be overlooked or, what is worse, described in a language that does not permit their detailed analysis and, in the end, they are ignored.

A philosophical theory of human action should explain how it transforms the environment and the people themselves. In this context, the person's intentions, motives, and goals must be considered. That is, the sense of human action. All this leads to a pragmatic interpretation of human action. From this point of view, transactionalism may be a fertile framework for this type of phenomena. But it is not clear if it is also useful to analyze the phenomena of learning, as the defenders of situated cognition claim.

Both in psychology and in artificial intelligence, the initial analyses were excessively structural, focusing on purely formal aspects because of the difficulties of the researchers' enterprise. The force of the experimental data gradually revealed the insufficiencies of the formal, or purely syntactic, analyses and gave way to a more dynamic and interactive view of an intelligent system's functioning,

\footnotetext{
3 Frege, considered the founder of analytic philosophy, would be at the antipode of Dewey's pragmatist functionalism, more related to the biologist viewpoints and those derived from social Darwinism.
} 
focused on more semantic aspects. Some time ago, from cognitive psychology, Holland, Holyoak, Nisbett, and Thagard (1986) called for a reorientation toward more pragmatic interpretations of learning. These authors did not hesitate to acknowledge that this reorientation had already occurred in the work of Anderson (1983), Mitchell (1982, 1983), and Rosembloom and Newell (1986), who explored how knowledge could be generated and used within the framework of problem-solving behavior, or in the work of Johnson-Laird (1983), another distinguished defender of symbolic theories, who showed that the mental models are transitory constructions of the environment that guide the processes of human inference. At this point, regarding these new conceptions of learning, one wonders whether these changes in cognitive psychology were the result of the analyses proceeding from transactionalism. Probably, the answer would be "no."

However, transactionalism has had a crucial influence on situated cognition, not only providing the basic ideas on which it is founded, but also transmitting the type of language and methods of query and reflection suitable for philosophy. This involves the risk of turning situated cognition into an umbrella for some versions of learning that cannot resist a detailed analysis. For example, consider the fact that people's goals are implicit in any human activity and, of course, in learning. But we wonder whether learning depends directly on the kind of mental operations people perform in the course of their goal-directed problem-solving behavior or, in a hasty generalization, on the intentionality generated by their interaction with the environment. In the latter case, one would have to acknowledge that, ultimately, intentions are what produces changes in knowledge. In fact, experiments carried out already several decades ago, in which learning occurring in intentional situations was compared with that occurring incidental learning situations, showed that the intention of learning does not affect learning (see, for example, Nelson, 1976).

From its very origin, the transactional viewpoint is closely linked to education, which, in turn, can lead to some misunderstandings, also as a result of some generalizations. A learning problem in educational settings can sometimes be mistaken for a problem of learning theory. For instance, education has sometimes been accused of trying to make students learn contents that make no sense to them and which, as a result, they do not learn. This is doubtless a serious problem for education. However, its analysis exceeds the limits of this article. But it is not a problem for learning theory. The fact that a learning theory must explain the role of goals in learning processes does not mean that it must determine the goals of learning in education, or that a reflection about the goals of education can turn into a learning theory.

Another possible source of confusions should be noted. For a learning theory derived from transactionalism, the transformations produced in the individual are as important as those that take place in the environment as a result of human action. However, what individuals learn is not the same as what collectives of persons or societies learn. To unravel the problems of what we have called "social learning" is a task for sociologists or anthropologists. In a sense, societies could be said to learn and build a culture but, in any event, the processes by which they "learn" should not be mistaken for the processes by which individuals learn.

Generally speaking, the interaction of individuals leads both to social and to individual learning, but the result of learning is not the same in society as in the individual. The nature of this "social learning" result—where is it, what is it like, and by what mechanisms is it used-exceeds the boundaries of a psychological learning theory. However, it seems obvious that, in individuals, the result of learning must somehow be represented in their minds and whatever has been recorded in their minds is used on later occasions. Naturally, the concept of mental representation cannot be applied to the result of social learning, and therefore, one must resort to functional units whose definition, once again, is the task of sociologists or anthropologists. On the other hand, as education can be considered a culturalization process - a process in which children assimilate the culture of the society in which they live, reconstructing the culture, it is a field in which individual learning is often confused with social learning. To sum up, denying the virtuality of mental representations makes sense in social learning but not in people's individual learning, unless, in a display of intellectual distortion, one denies the existence of individual learning and reduces everything to social learning.

With regard to the second point, Ryle (1949) introduced the distinction between knowing what and knowing how. According to this philosopher, knowing what is knowledge that describes the way the world is, whereas knowing how is knowledge about how to do things. Knowing how is usable knowledge. Contrariwise, knowing what is inert knowledge that is only good for being stated. Ryle, who was also interested in education, thought that the failure of institutional teaching was due to its emphasis on transmitting knowing what, which is knowledge that is not directly usable. Hence, the senselessness of the educational practices.

Ryle's (1949) distinction was incorporated some time ago into psychology in the analyses performed on learning, but not because of Ryle's direct influence, but as a consequence of the development of psychological learning theories, starting with the primitive works of Newell and Simon (1972), Newell (1973), and Anderson (1976). In psychology and artificial intelligence, knowing what is known as declarative knowledge, which is knowledge that describes the way the world is, whereas knowing how is called procedural knowledge. In computer sciences, it would be like the difference between data and processes.

Among the many declarations of situated cognition about cognitive psychology, is the accusation that cognitive psychology underscores knowing what knowledge. Namely, 
according to situated cognition, psychology considers knowledge to be something conceptual, fixed, and inert, due to some hardening of the mental representations. Yet, indeed, only from cognitive psychology can the meaning of declarative knowledge-how it is used and how it contributes to the acquisition of procedural knowledge-be understood.

The psychological analyses of the nature of declarative and procedural knowledge allow us to understand their interrelation, why people have declarative knowledge, and how, from declarative knowledge, people acquire procedural knowledge, which is the only really useable knowledge. In fact, it also allows us to understand the tendency in education to transmit only declarative knowledge, an extreme that is at the core of Ryle's (1949) criticisms of institutional education. The reason is that, as procedural knowledge is highly automatized, people are aware of their declarative knowledge, and therefore, when they try to teach their knowledge, they tend to think in declarative knowledge. Lastly, one can understand why the persistence of education in teaching declarative knowledge reinforces the much criticized "transmission model." Declarative knowledge is the only knowledge that can be stated or declared and, consequently, the one that is the most apt to be transmitted to a supposedly passive learner.

The absence of a scientific analysis of Ryle's (1949) considerations has led to a strange paradox that is found in some versions of constructivism in education. The paradox starts with a strong rejection of the "transmission model" and of teachers' erroneous preconception that students are passive learners. However, at the same time, teachers are led to believe that what they should teach is declarative knowledge, regardless of the use to which such knowledge is put, namely, unrelated to the procedural knowledge which it could produce. All this ultimately promotes the "transmission model" whose very criticism was the starting point.

Fortunately, situated cognition does not share this approach coming from other versions of constructivism, according to which knowledge is reduced to declarative knowledge. However, it is symptomatic that, Ryle's (1949) contribution does not lead to a reflection in situated cognition on the nature of these two types of knowledge, but instead it only takes note of his warning about the importance of the use of knowledge. For situated cognition, knowledge could be redefined as the skill to behave interactively with the environment. In this sense, it would not be the sum of concepts and relations inside a person's head. That is, it would not be of a declarative nature. In its origin, knowledge would be fruit of exchanges between individuals and their environment and, consequently, it would only be useable in the same context in which it was learned. Therefore, it is characterized by some unrepeatability which we will come back to later. For the time being, suffice to say that such unrepeatability leads to ignoring the existence of declarative knowledge. If knowledge is unrepeatable, why bother storing something that cannot be used in the future?

This lack of considering declarative knowledge leads to an insufficient image of how learning takes place. From situated cognition, it is impossible to understand why people have declarative knowledge and what its function is within the system. In some versions of situated cognition, people's declarative knowledge is understood as a subproduct or residue of their problem-solving activity. Brown, Collins, and Duguid (1989), for example, propose that, in educational situations, students should acquire declarative knowledge by a process of reflection about the procedures they already master. Regarding this contempt for declarative knowledge, it is one thing for the problem of education to consist of having limited itself to transmitting declarative knowledge, but to ignore the existence of this kind of knowledge and its function within the system it is quite different. Declarative knowledge is certainly inert if taken by itself, but we all know that Paris is the capital of France, tables have legs, and dogs bark. What we should try to do is to explain how this knowledge can be used and what function it fulfills in our problem-solving behavior.

As situated cognition does not study in depth the distinction between declarative and procedural knowledge, some of its versions may not explicitly deny the existence of declarative knowledge. In this case, it only states that declarative knowledge depends on the context, in the sense that it can only be used in the context in which it was learned. The point is that declarative knowledge, for example, conceptual knowledge, is relatively independent of the context and precisely therein is its virtuality. In any case, in the explanations of learning by situated cognition, declarative knowledge is ultimately ignored.

With reference to the third point, Searle (1980), a philosopher initially oriented towards linguistic philosophy, underlined the differences between computers and the human mind. In his famous "Chinese room" example, an Englishspeaking man going from side to side of a room, following the instructions of a computer that simulated a Chinesespeaking person, could give the impression to an external Chinese-speaking observer that he knew Chinese, when in fact he did not know the meaning of any of the Chinese symbols he was dealing with. With this example, Searle wished to point out the fact that computers display intelligent behavior, although radically different from peoples' behavior, because the symbols used by computers have no meaning. For Searle $(1980,1983,1984)$, the intelligent operations performed by computers only obey syntax, so these operations can be characterized as purely formal. But the operations performed by the human mind are based on representations that have meaning and are consequently defined by their semantic nature.

Although Searle cannot be actually ranked within situated cognition or Dewey's (Dewey, 1942; Dewey \& Bentley 1949) transactionalism, his emphasis on the 
difference between the syntactic and the semantic and his attempt to situate psychology in the syntactic sphereleaving semantic matters in the hands of the highest bettorhave frequently been used to support the viewpoint of situated cognition, while devaluating the viewpoints of cognitive psychology. Situated cognition is clearly oriented towards the problem of sense and believes that meaning and, ultimately, the sense of human action, can only be grasped by the exchanges with the environment, because the sense is generated in the framework of these exchanges. Probably, nobody will object to this viewpoint. However, when this view is stressed by referring to Searle's arguments in the attempt to establish an alternative to cognitive psychology, then some problems arise.

In the first place, some confusion arises about the aforementioned old distinction between sense and reference. When stating that the symbols that computers use lack semanticity, it can mean that they have no referent. It can also mean that computers have no sense and that it is the user who provides the sense, but this involves other issues that will be commented on hereafter. When referring to the first meaning of the semanticity of symbols, it should be made clear that, although the symbols used by computers lack meaning, the psychological theories of learning do not deny the semanticity of mental representations. Moreover, the work of Marr (1982) has even demonstrated that the semanticity of mental representations originates in perception and one could speculate about the possibility that the symbols used by computers lack semanticity simply because computers lack perceptive organs.

Ultimately, the problem lies in knowing whether the nature of the operations carried out by an intelligent system can be different because of having or not having meaningful representations. If so, the task would consist of explaining how semantics determines syntax. None of these two aspects of the problem has been seriously addressed or solved. The semanticity of mental representations can certainly affect the nature of mental operations, but what really should be explained is how a syntax of such a radically different nature could emerge from this semanticity. Lacking such an explanation, any consideration of this sort is mere assumption and consequently, of no value. Therefore, to point out this difference between computers and the human mind is a mere anecdote. In Linguistics, for example, where a similar issue - the relations between semantics and syntax-has been debated ad nauseum, no solution has been found. Briefly, in this field, it seems that the only possible solution is to resort to Pragmatics to explain how meaning depends on the context and the speaker's intentions and, therefore, the only way to understand "what the speaker wants to say" is to take these factors into account. That is, an explanation is provided that everyone has in mind, but using a relatively sophisticated language. Unless, of course, the context and the speaker's intentions are precisely defined, and from that definition, one can understand how the context and the speaker's intention can determine the meaning. In the applied field, for example, the sterility of these analyses has checked the development of a computer program than can simply translate a discourse from one language to another.

As mentioned, Searle's (1983) reflection also pointed out that the behavior of computers lacks sense. This is because computers have no goals or, ultimately, intentionality. As computers are physical systems that manipulate symbols and, according to the symbolic theories, so is the mind, these theories are accused of identifying computers with the mind and, in a hasty deduction, the conclusion is reached that in the symbolic theories that are typical of cognitive psychology, there is no place for goal-directed intentional behavior.

This is not the right place to examine in detail the insufficiencies of this argument. Suffice to say that the symbolic theories have been able to develop explanations of goal-directed behavior that are supported by a large amount of experimental data. On the other hand, to state that both the human mind and the computers display intelligence because they are both physical systems that manipulate symbols cannot lead to the naivety of declaring that, if this is so, then the mind is like a computer and, therefore, it lacks intentionality. Some time ago, it was speculated whether the so-called "computer metaphor" of the mind could be considered a strong or a weak metaphor, in an attempt to decide to what extent the mind could be identified with a computer, or in what way. This speculation is not very fruitful, especially if we do not understand what is meant when declared that the mind, like the computer ${ }^{4}$, is a physical system that can manipulate symbols. From the viewpoint of research on the functioning of the mind, it would be interesting to decide whether the functional architecture of a computer can inspire our theories of the mind. At the start of cognitive psychology, an affirmative viewpoint of this possibility was adopted. It is probably in this sense that one could argue about whether the computer is a strong or weak metaphor of the mind. The current issue is exactly the opposite: The scientists who develop computers are inspired by what psychology knows about the functioning of the mind. In this sense, it would be more suitable to refer to "the metaphor of the mind."

The main problem about Searle's (1980, 1983, 1984) speculation is the aforementioned one about many analyses proceeding from philosophy and which consist of the use of abstract terms that lack an operational referent. Many authors agree that terms such as intentionality, comprehension, or

\footnotetext{
4 A description of the nature of the physical systems of symbols may be found in Newell (1980) or, more recently, in Newell,
} Rosenbloom, and Laird (1989). 
semanticity may belong to this category of abstract terms lacking a clear referent. The issue of intentionality, for example, has become very popular in some philosophical circles where they argue heatedly about this mysterious characteristic, supposedly only possessed by the human mind. The point is that intentionality is never defined with precision. In general, philosophers usually talk of aboutness (which could be understood as "something about something"), that is, for philosophers, intentional behavior is behavior that refers to something. For example, if we say "a sunset is beautiful," we are referring to something, and in this sense, it is intentional. Thus, in philosophy, intentionality is usually linked to sense and meaning. However, at a more concrete level, intentionality could sometimes refer to people's beliefs and desires, other times to goals, and even to awareness of the goals, or probably to other things as well.

When analyzing Searle's (1983) writings, it seems as if intentionality or meaning were some sort of hidden substances secreted by the human brain. Some time ago, Pylyshyn (1980) used a jocose argument to respond to Searle's obsession with computers and his Chinese room metaphor. He said, let us imagine that technology advances so far that it can substitute a person's injured brain cell with a pill or chip, programmed to maintain the same inputoutput function of the injured cell. If we progressively substituted more and more cells, there would come a time in which the person would go on talking correctly, but he would not know what he was saying; that is, he would have lost the capacity to understand the meaning. What external observers would understand as words would only be sounds produced by circuits for that person. Naturally, some philosophers do not accept this joke because for them, intentionality - that property of persons that they are incapable of defining - would be an attribute of the mind and not of the brain, but then, we would be entering the risky assumption of the mind-brain duality, whose discussion exceeds the limits of this article.

Fortunately, Searle is not a dualist, so many ask him the following question: How can one decide whether or not a system has intentionality when in both cases, they have functional isomorphism; namely, they both do the same thing? Searle's (1984) answer is that every person in particular knows that we have a mind and that our mind is intentional and we suppose that the same thing occurs with everyone else, simply because we are made of the same stuff. Robots, computers, and other similar creatures, at least for the time being, are made of a different stuff and, consequently, we cannot assign them this characteristic of intentionality. Searle's argument does not seem very conclusive. In the Chinese room metaphor, where a person blindly follows some instructions without knowing the meaning of what he is doing, we could add several persons, or even stupid beings that, by following instructions, would make the system work. It is not clear whether such a system is different from any normal person. Especially, if we think, like Harman (1989), that "Our brains work as they do because they are full of tiny little organisms (brain cells) that stupidly follow certain limited principles!" (p. 838).

This is not an attempt to deny the presence of some unsolved problems in psychology through the reflections on intentionality or consciousness. But we cannot rule out the possibility that the entity of these possible problems derives precisely from their lack of definition. Anyhow, the interesting point is that when situated cognition assumes Searle's arguments, this adds more confusion to its own stance and, when attempting to present itself, using those same arguments, as an alternative to the symbolic theories of psychology, it makes both positions incompatible. The undesirable result is that the somewhat globalizing analyses of situated cognition, which might be correct, lose their possible efficacy by not being complemented with the more rigorous analyses proceeding from cognitive psychology.

\section{Vigotski's Sociocultural Theory}

In the twenties and thirties of the $20^{\text {th }}$ century, Vigotski $(1934 / 1962,1978)$ established a developmental theory within the framework of a broader conception of human action. This conception, known as the activity theory and which was also developed by other authors, such as Luria (1976) or Leontiev (1978), attempted to explain the origin of consciousness from what they understood to be a Marxist perspective ${ }^{5}$. The essential idea is that individual consciousness would emerge as the fruit of social interaction, which, in turn, is supported by language. We cannot refrain from establishing some parallelism between this stance and Skinner's (see Lowe, 1983), with which we do not disagree ${ }^{6}$. It is not a question of denying the virtuality of the activity theory to explain the origin of consciousness, but rather of examining whether some analysis that would contribute to explain the phenomenon of learning may derive from this theory.

Surprisingly enough, this conception about human activity shares some points with Dewey's (Dewey, 1942; Dewey \& Bentley, 1949) transactionalism, which has turned it into one of the main references of situated cognition. At this point, we note that another important developmental theory, Piaget's theory-which also claims to be of constructivist nature-, cannot be considered transactionalist because of the minor role assigned to the environment in

\footnotetext{
5 For a reflection on Marxism and psychological theories, see Aparicio (1986).

6 Some clues to this identification may be found in Aparicio (1991).
} 
ontogenetic development. Coming back to Vigotski (1934/1962, 1978), developmental growth can be analyzed at several levels. Leaving aside the madurative and phylogenetic levels, the most developmental level, the ontogenetic, or macrogenetic, level occurs through an internalization process of interindividual exchanges.

Vigotski's (1934/1962, 1978) explanations about the internalization process, although diffuse, have some noteworthy merits. For Vigotski, internalization does not only refer to what could be understood as the static content of learning, but also to the internalization of the very processes. That is, in the course of interactive problem-solving, not only is the solution to the problem internalized but also the process by which it is solved. Seen from this angle, the problem proposed by internalization has led to research of the metacognitive aspects of learning, which has doubtless implied significant progress in our knowledge of learning, although probably not directly through Vigotski's influence. On the contrary, especially when seen from an educational perspective, internalization can be contemplated as a culturalization process, with the resulting risk of blurring the distinction between "social learning" and individual learning. According to Vigotski's theory, in this internalization process, language - which has the function of regulating thinkingplays a major role (as with Skinner, 1974, 1984), becoming the link between the interpersonal and intrapersonal spheres.

A parallelism is postulated between this ontogenetic, or macrogenetic, level, and another one, the epigenetic level, which Vigotski (1978) called the microgenetic level and which corresponds with individual learning. Thus, along with other developmental theories such as Piaget's, this theory shares the claim that it can explain people's individual learning in similar terms to those that supposedly take place in developmental growth. In contrast, it is noteworthy that, as the explanations about development provided by some developmental theories are based on dubious developmental stages, cognitive psychology tends to invert the strategy and to explain ontogenetic development in terms of individual learning, considering children as universal novices.

At the microgenetic or individual learning level, Vigotski's (1978) theory postulated some mechanisms similar to those postulated at the ontogenetic development level, so that learning would consist of the internalization of social processes of an interactive nature. One of the most noteworthy characteristics of the explanations of learning derived from the Vigotskian model is its generality. Although the advantage of these general analyses is that they make the lay person feel that he understands how learning is produced-which is probably why they have been successful in some educational circles-however, they have the tremendous drawback of validating some interpretations of the phenomenon of learning that, at the very least, could be described as extravagant.

Thus, for Vigotski (1978), like developmental growth, learning takes place in a social context and is the result of social interaction. Naturally, Vigotski does not deny the possibility that individuals may solve problems by themselves - although, obviously, he does not say howbut he states that there are some difficulty levels where problems may be solved cooperatively, but not individually. Vigotski calls this the zone of proximal development. This notion, which plays an essential role in his explanations of the process of ontogenetic development, is also essential in the explanations at the microgenetic level. Progress in learning takes place through the changes produced in this critical zone. On the other hand, as these changes are the result of social interaction, then this interaction is produced in the aforementioned proximate development zone. In a teaching situation, for example, teachers should make an effort to interact with their students in this zone if they want them to learn, but the teachers can also enhance interaction between the students, who presumably share the same critical development zone. The interaction of a child with an adult, or of the beginner with the expert in the case of learning, is, in principle, not so beneficial because their respective zones of proximal development are very unbalanced. At a deeper level, this inequality can be understood as more than the mere difference in the quantity or nature of knowledge. It is an inequality that is due to the difference in meaning. That is, the zones of proximal development are different insofar as the subjects' type of problems and goals are also different. In his analysis of the mediation of language in the process of development, for example, Vigotski (1934/1962) points out that the child and the adult share the reference before they share the meaning.

Intuitively, to understand the zone of proximal development in terms of sense is somewhat attractive. However, from an experimental perspective, there are certain difficulties to define with some precision the differences between the possible "senses" in order to predict in which zone of proximal development a subject is. Perhaps for situated cognition, this is not a real problem because there is ultimately the possibility of making holistic considerations, but we should acknowledge that if one attempts to study the topic in depth, either for any kind of research or to apply this notion, for example, to educational settings, this lack of definition effectively prevents the idea of proximal development from bearing fruit.

Sometimes Vigotski's (1978) concept of proximal development has been combined with Piaget's idea of conflict. This combination has produced the notion of sociocognitive conflict, in an effort to explain how learning takes place when an experience comes into conflict with the available knowledge, but only if this occurs via a social interaction in a certain critical zone of proximal development. This reformulation is illustrative because it also stumbles upon the lack of definition of the notion of zone of proximal development. However, when introducing the Piagetian notion of conflict with preexisting knowledge, the analyses take on a more cognitive and less psychosocial quality and 
then, when these analyses are applied to educational settings, what is ultimately left is the old yearning, present in teaching for decades, of defining what knowledge is required to be able to acquire new knowledge. Namely, what is known as the prerequisites of learning. Moreover, the very idea that conflict can produce learning is only sustainable when it is formulated very generally. For example, in the field of research on conceptual change, where it has been profusely mentioned, this idea has been revealed to lack explanatory power (see, for example, Rodriguez Moneo, 1999) and is quite dubious that it can describe the mechanisms of conceptual change (see Aparicio \& Rodriguez Moneo, 2000).

Vigotski's (1978) sociocultural theory is clearly transactional and has therefore become one of the foundations of situated cognition. Learning is understood as a product of social interaction and, consequently, strongly dependent on context. However, Vigotski's contribution to situated cognition goes beyond its synchronization with the transactionalist viewpoint. Concretely, its explanatory model allows the detailed examination of two characteristic aspects of situated cognition regarding teaching. In the first place, the roots of the difference between everyday knowledge and academic knowledge or, in other words, between naïve and scientific knowledge. Second, it contributes to the development of the idea, already present in transactionalism, that learning is generated in group interaction situations. In some versions, the possibility of learning by oneself is even denied, which, as will be seen, poses numerous problems.

With regard to the first point, learning takes place in the context of real life and is, in principle, learning between peers, which means it is produced in the same proximate development zone. The nature of this learning would consequently be the result of some co-participation in the goals and type of problems to be solved. A theory about human activity may be able to explain why people learn what they learn as a function of the context in which they learn. The point is whether it can explain how people learn what they learn, which would be the object of a learning theory. As we shall see, there is, in fact, a flagrant lack of ideas about the learning mechanisms that occur in real life situations, which derives from the assumptions of situated cognition.

Regarding group learning, the notion of zone of proximal development is also essential because, as mentioned, the efficacy of learning between peers is based on the fact that such learning takes place in the same proximal developmental zone. But is this explanation is sufficient? As noted, the notion of proximal developmental zone may be relevant to describe the nature of social interaction, but not to build thereon a theory of group learning processes. In fact, the enthusiasm with which the field of teaching has greeted the efficacy of cooperative learning is parallel to the lack of guidelines about its possible practice, except, of course, those guidelines of a motivational nature, based on the structure of the incentive (Slavin, 1995). Moreover, despite the unconditional approval that some teaching spheres have expressed for this method, the corresponding research does not seem to have shown its efficacy conclusively (Druckman \& Bjork, 1994). Actually, we lack adequate analyses that would allow us to understand how people learn in groups. Except for the dubious aforementioned explanations about the role of conflict in groups of peers, there is only one wellknown learning mechanism left, extensively studied in psychology, consisting of elaboration (Slavin). The elaboration that is enhanced in group situations is of a very secondary nature, such as when the group is not exactly a peer group and some members teach others. As has been frequently shown, when individuals try to teach another person, they force themselves to elaborate their own knowledge, which enhances their own progress or learning.

As with Dewey's (Dewey \& Bentley, 1949) transactionalism, what must be determined about Vigotski's work is whether an alternative learning theory from the one provided by cognitive psychology can be derived from a theory of human activity. In the case of Vigotski, the trajectory is somewhat more complicated because from a theory of human action would derive a developmental theory from which, in turn would derive a learning theory.

\section{Ethnography}

Until the beginning of the $20^{\text {th }}$ century, ethnography, which focused on the study of the inhabitants of the European colonies of Asia and Africa, was merely descriptive. But Malinowski (1961/1922) began to query about the meaning of the cultural practices of these supposed barbarians. The tale of how Malinowski transformed the field of social anthropology is a long one and exceeds the limits of this article, but it is important to remember that Malinowski carried out a work in the search for meaning.

Mead (1928) soon picked up the relay in a study on adolescence in Samoa that can be considered the first monograph on educational ethnography. Although some doubt has subsequently been cast on the sources from which Mead reached her conclusions, the Malinowskian methods of Margaret Mead were first applied to the investigation of teaching by Spindler in Stanford and afterwards by Kimball in the Teachers' College of Columbia. Later on, Stenhouse transferred the assumptions of educational ethnography to England.

The important thing from this current of thought, which proposed the use of qualitative research methods, is that its main goal was to reveal the meaning of educational exchanges. Among the important findings of this type of focus is the analysis of the tacit contents that are transmitted in education, which are technically called the hidden curriculum. However, the limitations of the qualitative research methods, together with the inherent subjectivity of the interpretative focus in this kind of theoretical perspective led to a dead end that, nonetheless, caused some concern for the meaning of teaching to be maintained. 
As of the end of the seventies, some anthropologists, among them Lave (1988), once again took an interest in education from the ethnographic view in an attempt to unveil the meaning of educational practices. This investigator's strategy consisted of establishing the differences between daily or informal knowledge and academic or formal knowledge. The idea is that most school activity is produced in the context of a relatively closed culture that has nothing to do with the culture underlying the activity that takes place in people's daily lives. Thus, the purposes and the meaning of the exchanges that take place in real life are completely different from those that occur at school. The problem of meaning, inherited from ethnography, merges in Lave's approach with the transactionalist perspective via the influence from Vigotski's sociocultural theory (see Rogoff \& Lave, 1984). Thus, Lave has become one of the most qualified representatives of situated cognition.

According to Lave (1977), the most important thing is that the way people learn at school is different from the way they learn in real life. In both cases, the context is the determinant factor. Therefore, there seems to be a notable lack of transfer from one situation to another. For example, in a study by Lave (1988) on the behavior of the clients of supermarkets from Orange County in California, she observed that the clients' academic level in math did not correlate with their capacity to calculate the best price. That is, the estimation of whether it was better to buy a 17-ounce can of tomatoes at 30 cents or a 25 -ounce can at 41 cents requires somewhat complicated fraction operations that the supermarket clients master, but it has nothing to do with what they learned at school about operations with fractions.

Moreover, Lave (1988) discovered some interesting interrelations. For example, she verified a strong correlation between income level, knowledge of academic mathematics, and academic level, but none of these variables were related to the ability to select the best price at a supermarket. The relation between income level and academic level has been repeatedly demonstrated ever since the classic work of Comber and Keeves (1973), although it was subsequently refined, in the sense that the correlation only appeared in middle classes, but not in the less favored ones.

Anyhow, the correlation between income level and knowledge of academic mathematics, and the lack of a relation between academic and everyday knowledge, led Lave to some excesses, not lacking interest, according to which academic mathematics are only good for defining the class structure of the American society. This lack of meaning of teaching led her to conclude that academic mathematics are as arbitrary and irrelevant as Latin and Greek were in past generations, which would explain why there is no relation between knowledge of academic mathematics and the ability to select the best price at a supermarket, despite which the relation persists between the academic and the income levels.
In another well-known study of Carraher, Carraher, and Schlieman (1985), street children from Recife (Brazil) were observed to be capable of performing complicated mathematical operations in the course of their sales on the street, and they also verified that this skill was not transferred to school. In these and other studies, these two types of skills are shown to co-exist independently. This has led Brown et al. (1989) to distinguish between an authentic activity and a school activity, which is not authentic and is characterized by being unproductive from the perspective of useful thinking.

In order to understand what authentic activity is, we go back to Lave's study of consumer behavior. In this situation, there are other factors that intervene and determine buyer behavior, for example, the quantity of a product needed depending on the size of the family or how near a certain product is on the supermarket shelf may determine a more expensive sale. Thus, the buyer's decision is determined by the context, where many factors interact.

Lave (1988) used this framework of analysis to understand the behavior of "normal people" in their daily activity. Her studies reveal the large difference between the activities and the culture that provide meaning and goals to what students learn in real life and at school. Specifically, regarding the very processes of learning, Lave thinks that there is a notable difference between the way people learn at school and the way they learn in real life. When people want to learn something, there are two options. First, to adopt the classic role of the apprentice who tries to learn from what others do, by interaction with them. To adopt this apprenticeship role does not involve a qualitative change of what "normal people" do, so the behavior displayed by apprentices is very similar to that which takes place in real life exchanges (Lave, 1977). A second alternative is to sign up for a course or become a student at a school. In this case, the general strategies of intuitive reasoning, problem-solving, and negotiation of meaning developed by people during their daily activity must be substituted by other strategies that are more appropriate to solve clearly defined problems, formal definitions, and precise manipulations of symbols.

It is probably difficult to object to anything in Lave's (1988) viewpoints regarding the difference in meaning between real life and school exchanges. However, her views on learning are a different matter. To say that the learning of an apprentice is more efficient than the learning that takes place at school is not very useful unless one actually demonstrates that the former is effectively more efficient and, if so, unless one finds out how the apprentice actually learns. To know this, one must investigate the processes displayed by the learner in this type of situations and not restrict oneself to what could be called motivational considerations. As the learning processes from daily life are ignored in situated cognition, it is symptomatic that when applying situated cognition to the field of education, these processes are not enhanced, but instead they try to make 
the academic situations as similar as possible to daily situations in the hopes that if the situations are the same, the learning will be equivalent.

At this point, readers are reminded of a historical event that may illustrate what we mean in this discussion. Skinner, a pioneer in transferring the findings from psychology of learning to education, proposed applying to teaching the idea that learning is produced as a consequence of reinforcement (Skinner, 1974). Actually, it seemed as if he was applying a learning theory to education. However, when cognitive psychology began to focus on learning, the researchers became aware of the fact that reinforcement was more a question of motivation than of learning (Kintsch, 1977). Learning that takes place in instrumental or operant situations can certainly be considered learning, if it is understood that subjects learn the relation between their behavior and the consequences derived from it. But if, as in the case of Skinner, we ignore this theoretical intermediation and simply say that learning is the product of reinforcement, then we are talking about motivation, not learning. This is similar to the case of situated cognition that, in its rather globalizing analyses, does not clarify what is learning and what is motivation to learn. Moreover, whereas in Skinner's case, his contribution to motivational theories-and, in a sense, to learning - is clear, the same cannot be said about situated cognition. Perhaps an additional work could be carried out to attempt to analyze what situated cognition contributes to the theories of motivation, parallel to this article about its contribution to the theories of learning.

\section{Situated Cognition and Cognitive Psychology}

In the previous section, we attempted to dissect the series of ideas that merge in situated cognition and to examine the extent to which some of them are relevant to the analysis of the phenomenon of learning. The lack of rigor of some formulations of situated cognition may lead to confounding, for example, a problem of learning with an educational problem; a problem of learning with a motivational problem; or a problem of social learning with an individual learning problem. In addition, situated cognition has frequently attempted to define issues against the assumptions of cognitive psychology. This has led to rather simple views of the standpoint of cognitive psychology, which we have attempted to clarify.

In fact, rather than lack of rigor itself, situated cognition uses a different level of analysis from that of cognitive psychology (Greeno, 1998). According to Greeno, a mathematician and enthusiast of learning and, currently one of the greatest defenders of situated cognition, the level of analysis of situated cognition is that of global interactive systems and, consequently, it starts out from the kind of models of human activity proposed by Dewey (Dewey, 1942; Dewey \& Bentley, 1949) or Vigotski (1958). This level may be useful to analyze phenomena related with systems of socially organized activity and it may be the most appropriate to address the problem of the sense of human action. Hence, its arrival on the scene of the problem of meaning. In contrast to this level of interactive systems is the level of analysis of cognitive psychology, which could be defined as that of individual cognition. What we are trying to defend here is that the phenomenon of learning belongs at this level, which is held by cognitive psychology.

These two levels of analysis do not have to be contradictory; they could even be complementary. The problem arises when, from a certain viewpoint of analysis, one attempts to address issues that are impossible to address from that viewpoint. This does not mean that the findings at one level cannot contribute to a better understanding of the findings at another level, as long as this communication does not involve the invasion of one field by the other. And not because the competencies of the different disciplinarian fields must be salvaged, but because conceptual systems and theoretical frames of reference are generated about a certain type of problems and to analyze certain phenomena. Unless reference frames from other fields are imported with some rigor, the result is a whole series of misunderstandings and inconsistencies that have already been discussed.

For example, education is an applied activity that poses many problems. One of them is individual learning and another is the meaning of education. The issue of the meaning of education, which is a philosophical problem, could be expressed by the question: what use to our students is what we teach them? This problem refers to the goals of teaching and can undoubtedly only be addressed from an analysis that takes into account human activity within the framework of a socially organized interactive system. To attempt to solve the problem using explanations from a learning theory is a bit absurd, although a learning theory could contribute somewhat to clarify some extremes. In the example we discussed above, the consideration that declarative knowledge is not directly useable whereas procedural knowledge is, may help to delimit the problem.

Furthermore, in the description of situated cognition with regard to education, it seems as though this current of thought finds itself incapable of solving the problem-the sense of teaching-for which it is supposedly equipped and, instead, is trying to turn it into a learning problem. It would therefore not be a question of knowing whether what we teach makes any sense to our students but to try to lend it sense by contextualizing learning. This way of looking at things leads to a teaching strategy that has found some favor among educators. An interactive theory of human action states that if we manage to design a meaningful context for our students, learning will ultimately be meaningful, and if the context is realistic, the resulting learning will be used because the corresponding transfer is guaranteed. Once again, it seems we are facing a motivational problem. However, from the perspective of a learning theory, the issue is to 
know how learning process can be facilitated in certain motivational conditions and to know the transfer limits and possibilities of what is learned.

The possible achievements of situated cognition in posing some interesting problems are obscured by the nature of its analyses of learning, which are somewhat naïve or, to use the above-mentioned argument, which use conceptual frameworks that are not very appropriate to analyze the phenomenon of learning. Our opinion is that it would be necessary to arrive at some convergence of these two approaches, which would entail adopting a common language, a task made difficult because of the intellectual roots of situated cognition.

Fortunately, situated cognition has gone into less speculative fields, such as artificial intelligence (Agre \& Chapman, 1987; Clancey, 1992), where some specific problems have arisen such as the man-machine interaction; or robotics (Brooks, 1991), where it is necessary to integrate perceptive, planning, and motor systems. This has forced researchers to be more rigorous in the language that describes the possible discrepancy between situated cognition and cognitive psychology or, in artificial intelligence, between the stance of situated cognition and the symbolic viewpoint.

From this point of view, the main contribution of situated cognition could be summed up as follows: Cognition cannot be explained in terms of a representational model in which the contents are independent of the context. In principle, this statement does not seem to challenge the theories of learning proceeding from cognitive psychology. However, two possible standpoints have derived from this statement: one that could be considered weaker and another, more radical, one. The weaker view states that the inferences of a symbolic model that interacts with the environment, on the one hand, are strongly determined and controlled by the environment and, on the other, they must be susceptible to change by inputs coming from the environment. That is, the use of knowledge in a certain context significantly changes that knowledge. This statement does not challenge the psychological theories of learning either.

However, the radical position goes further when establishing that the influence of the environment is so great that the functioning of the human mind should be explained in terms of a purely reactive system-similar to the one conceived by some primitive behaviorists - that interacts directly with the environment without resorting to possible symbolic descriptions that already existed in the system. The radical stance is incompatible with the analyses of learning from cognitive psychology. That is, from this viewpoint, the analyses based on the hypothesis that the mind can be conceptualized as a physical system of symbols are directly rejected. This radical view of situated cognition is at least questionable, if not decidedly mistaken. For Vera and Simon (1993), the hypothesis of the physical system of symbols has been a fruitful paradigm in which cognitive psychology has allowed the experts to reveal many behaviors and, in artificial intelligence, to reproduce these same behaviors. In contrast, if the viewpoint of the radical stance is adopted, one cannot know with any certainty what predictions can be made and which experiments to carry out. That is, according to Vera and Simon, the series of hypotheses that make up the radical stance is indefeasible and, consequently, should be classified as unscientific.

In contrast to the radical stance, what we have called the weak standpoint is compatible with the analyses of cognitive psychology, as long as they do not try to make some hasty transfers from one field to another. A careful scrutiny is necessary to determine precisely what situated cognition contributes to the psychological theories of learning. Regarding this problem, cognitive psychology has not rewarded situated cognition theoreticians' diligence in reaffirming their stance by paying attention to situated cognition. In fact, cognitive psychologists have acted rather indifferent toward situated cognition.

Anderson, Reder, and Simon (1996) are an exception to this tendency. They have made an effort to determine precisely which vindications of situated cognition regarding learning might be far from those of cognitive psychology. They reached the conclusion that these vindications are not based on the available experimental data and, in some cases, they contradict these data. Precisely, this lack of scientific foundation of some of the excesses of situated cognition is what allows it to assign itself the role of the alternative to cognitive psychology.

It should be noted that Anderson et al.'s (1996) considerations refer to the learning that takes place in teaching, which is the main field of the digressions of situated cognition. Moreover, in the field of teaching, teaching mathematics is emphasized because this is the area (for reasons too lengthy to go into) where situated cognition has performed most of its analyses.

We would like to point out the importance for situated cognition of the contextualization of learning, derived from the need for learning to make sense, and not from a previous reflection about the nature of learning processes. This reflection is subsequent and, as it is strongly inspired by the former problem, it leads to some obviously unfocused generalizations. What could be considered the achievements of situated cognition are also the origin of its difficulties when attempting to transfer its analyses to the field of learning.

There is an additional problem. The possibility that learning takes place in the most realistic context has certain limits. In education, it is not always possible to achieve the desirable degree of realism. On the other hand, some skills cannot be acquired in exactly the same situation in which they will ultimately be used. For example, think of the amount of airplanes that would crash if pilots had to learn to fly by actually piloting airplanes. Furthermore, learning certain skills requires the prior mastery of a general basic declarative knowledge that allows one to solve problems and to acquire procedures. All this poses the problem of the 
generalization of learning some materials to other materials, learning transfer, and the translation of declarative knowledge to procedural knowledge. The value of a theory of learning is probably to be found here and it is just this type of research that blocks the conceptions of situated learning.

To come back to Anderson et al.'s (1996) detailed analysis, these authors sum up the main vindications of situated learning and conclude that none of these vindications in justified by the available experimental data, or they are contrary to these data. According to Anderson et al., the following four main vindications of situated cognition about learning could be contrary to cognitive psychology: (a) action is strongly grounded in the concrete situation in which it takes place, so that knowledge is specific to the specific situation in which the task is performed and, therefore, more general knowledge cannot be transferred to real life situations; (b) there is no transfer of knowledge acquired in the course of performing a task, which would facilitate learning another task; (c) teaching that is usually called theoretical and that refers to teaching abstract contents is not very efficient; (d) teaching must be provided in complex social environments in which a rich social interaction is produced that leads to learning between peers.

Naturally, situated cognition agrees with many other extremes that have been extensively studied in psychology, but the issue is to discover where the discrepancy lies, and the analysis outline of Anderson et al. (1996) seems correct to us. Therefore, we are going to use this outline to analyze the possible contributions of situated cognition.

Regarding the fact that action is closely related to the concrete situation in which it takes place and, therefore, learning is somewhat context-specific, is no problem for the explanations of learning provided by psychology. It is quite another thing to say (as situated cognition exaggerates) that all learning is context-specific and that more general knowledge lacks virtuality. This is like saying that we should not teach children how to multiply or that we should teach them to multiply in several different ways that happen in real life, and which might occur to us. It is not certain that our imagination would be able to anticipate all the possible real situations in which people might need to multiply throughout their lives, and, therefore, if general knowledge lacks virtuality, then we should probably not teach children how to multiply at school.

However, it is noted that, according to the study of Carraher et al. (1985), mentioned above, the street children from Brazil correctly calculate the cost of their sales and the change they should give the buyers, but they are incapable of solving arithmetic problems of similar difficulty at school. In our opinion, psychology can account for this phenomenon without resorting to arguments based on social interaction mechanisms. One possibility is that, at school, children are taught certain calculus algorithms and have pencil and paper at their disposal. The street children, however, not having pencil or paper, must employ different algorithms to optimize the capacity of their working memory, where they must mentally store the numbers to be calculated. Thus, street children may not master the algorithms required at school and hence, their failure to solve arithmetic problems that they easily solve in the street.

Perhaps, at school children should be taught to carry out mental calculus without the aid of pencil and paper, in which case, the children would probably have to make less effort than that required to learn the same thing on the streets. It is also possible that the children are more motivated on the streets than at school, so the additional effort they have to make on the streets goes unnoticed. However, it is not clear whether the algorithms learned this way are more useable than the traditional ones based on the use of pencil and paper. In any case, the study of Carraher et al. (1985) is a demonstration that some skills acquired out of school do not generalize to school, but it does not demonstrate that what is learned at school is never generalizable to real life problems. That is, it does not demonstrate, for example, that the arithmetic procedures learned at school will not be used later on by clerks in their transactions or by citizens in general when filing their income tax.

Lave's (1988) study about the behavior of supermarket clients shows that the skills learned in the school context may not transfer to some real life contexts. Probably, as we have seen, for the same reasons that some skills learned in real life do not transfer to school. However, there are some very important skills, such as reading, than transfer from one context to another with no difficulty. Furthermore, in students, not reading in their daily lives is a determinant factor of not mastering, or of reducing, their reading skills. This is one of the most extensively mentioned causes of socalled academic failure.

The context is certainly a determinant of learning but, if we wish to examine this in depth, we would have to start out by defining the context we refer to. Ceci and Roazzi (1994), for example, distinguish between a mental context, a physical context, and a social context. Although there is a strong interrelation between these three contexts, a rigorous theory of the consequences of the context on learning should clarify how each of these three contexts affects learning and how they are interrelated. According to Ceci and Roazzi, the context causes some knowledge structures, and not others, to become activated; it also makes a person carry out certain strategies that have been carried out in similar contexts at other times; and, lastly, it affects the subject's interpretation of the task itself.

There is no magic in the way the context affects learning. The effect of these three types of context has been extensively studied in psychology. In general, the context, whether it be mental, physical, or social, predisposes people towards a certain kind of mental operations, so that the elaborations made in one context are different from those made in another. In psychology of memory, for example, the coding specificity principle establishes that reinstatement 
of the context in which the coding took place determines recovery of the information to be recalled. Let us imagine that a person studies the word piano preceded by-that is, in the context of-the word heavy. The person should subsequently recall it either with the aid of the word music or the word heavy. As has been demonstrated ad nauseum, the presence of a retrieval cue in the memory test that allows subjects to retrieve the context in which they studied the word determines their ability to recall the word in question.

Thus, it is not a point of whether the context is more or less determinant, but of establishing the virtuality of more general knowledge, relatively independent of the context. In this field, there are many data that show how the process of decontextualization of knowledge determines whether it can be used in different situations. In fact, if one learns something in only one context, the material learned is closely linked to that context, whereas if one learns in various contexts, there is more generalization. Regarding an obvious case, the potential of general knowledge lies precisely in the fact that people can use their knowledge of, for example, tables without having to resort to the context in which they had their first experience with a table or to the various contexts in which they had experiences with tables.

With regard to the second vindication of situated cognition about the lack of transfer of knowledge when learning different tasks, although the two phenomena are related, one thing is the transfer between contexts and another, quite different, the transfer between tasks. If one considers the second point, the large volume of research carried out on this topic in psychology shows that there is transfer in some cases and not in others. Precisely, one of the big problems addressed by the psychological learning theories is learning transfer, and this is one of the greatest services that learning theories can offer to education, because, ultimately, education should be good for living. Although some very old studies were carried out in which transfer or lack of transfer was demonstrated in various situations, as current learning theories developed, this type of problem could be analyzed more specifically. In this sense, the main idea is that we are currently in a position to describe the learning processes with a considerable amount of detail and to analyze task components, so that we can identify the cognitive elements that intervene in learning.

Briefly, according to VanLehn (1989), there are currently two important approaches to learning transfer. The first is known as the identical elements theory (Kieras \& Bovair, 1986; Kieras \& Polson, 1985; Singley \& Anderson, 1985, 1989 ), and the second is based on the overlapping of semantic networks (Gentner, 1989; Holyoak, 1985). Regarding the first approach, the idea is that transfer is produced as a result of the coincidence of identical cognitive units. For example, Singley and Anderson have shown that subjects who have been trained in the use of a word processor learn more quickly how to use a second, different, processor and the degree of the first training transfer to the second is directly proportionate to the number of procedural elements shared by both word processors.

The second approach is about knowledge representation in semantic networks, so that transfer takes place by the amount of overlapping of the diverse networks. This mechanism has to do with analogical learning mechanisms. The two theories can be considered compatible hypotheses that analyze the phenomenon at different levels of analysis. The identical elements theory counts the number of units transferred, whereas the mapping theories attempt to explain exactly which parts of an element are transferred.

Regarding the fact that training in abstract is not efficient, this viewpoint of situated cognition derives from the idea that teaching should use procedures similar to those that take place in traditional training, defined by the teacher-learner relation. As mentioned, for Lave (1988), in this kind of training, the same kind of learning takes place as that which occurs in people's normal life. In this case, the problem also seems to become somewhat hazy as a result of reducing the learning problem to an issue of the contextualization of learning, which, no matter how important it is in teaching, theoretically speaking, is not the only factor to consider in a comprehensive learning theory. Although this is not the place to analyze this problem in depth, a learning theory must explain the function and the opportunity of what is commonly called theoretical teaching. It is generally agreed that the most efficient kind of teaching is that which combines abstract teaching with the study of cases and concrete examples. For Anderson et al. (1996), sometimes when real life problems are introduced, for example, to lend context to the study of algebra, a lot of time is wasted on secondary tasks such as making tables and charts instead of dedicating it to relating algebraic expressions to real life situations.

Regarding the learning that should take place in complex social environments, it can be considered a somewhat simplified adaptation of the analyses of learning by situated cognition. Data has indeed been obtained that show that sometimes, group learning is more efficient than individual learning. The point is that at other times, learning must be individual. Anderson et al. (1996) point out that in team sports or in orchestras, much more time is spent on individual than on collective practice, although both are necessary. But why is group learning efficient in some circumstances and individual learning in others? The answer to this question is only possible with the aid of a learning theory. The only specific analysis of situated cognition is the reference to learning between peers in the zone of proximal development, but this analysis is too general and is insufficient to adequately design an efficient situation for group learning. Imagine an alternative explanation, derived from the nature of procedural learning, according to which, at some stages of procedural learning, subjects are more aware of what they must do; that is, knowledge is less proceduralized and therefore, less automaticized. At this stage, it is easier to state explicitly what must be learned 
and therefore, the interaction between people who are in the course of acquiring procedural knowledge is more efficient than the interaction between someone who does not know and someone whose knowledge is very automaticized.

Greeno (1997) responded to these criticisms of Anderson et al. (1996) about the insufficient basis of what could be considered the alternative of situated learning to the cognitive theories of learning. As could be expected in view of the fact that the positions are ill defined, his answer focuses on the fact that Anderson et al. first caricaturize the stance of situated cognition and then aim their criticisms at that caricature. Anderson, Reder, and Simon (1997) respond that they are not referring to situated cognition, but to the possible contributions of situated cognition to learning. That is, they are not criticizing the analyses, which may be accurate, of situated cognition, for example, of the problem of the sense of human action. The important thing is to know what situated cognition contributes to a theory of learning, which is the topic of this article.

Without going into a detailed analysis of this interesting polemic, the issue is no longer whether some alternative learning theory to those of cognitive psychology derives from situated cognition, as this possibility has been discarded. Rather, the issue is to know how analyses at the level of interactive systems can contribute to analyses at the level of individual learning or vice versa. Vera and Simon (1993) believe that, in the current state of affairs of our knowledge, only a bottom-up contribution would make any sense, that is, from cognitive psychology and its corresponding analyses of individual learning to situated cognition.

In contrast, Greeno (1998) suggests three fields from which situated cognition could contribute to the enhancement of ideas that make up the theories of learning. In our opinion, this contribution is still not clear. In the first place, Greeno mentions the definition of the problem space. Starting with Newell and Simon (1972), the idea is that in the process of solving problems, the first step is to delimit the problem space. According to Greeno, the cognitive psychology theories have been developed based on the assumption of well defined problems. However, in real life, problems are usually ill defined because of the multiplicity of factors that intervene. This leads to the emergence of significant aspects of the problem in the course of problem-solving behavior. That is, when the environment in which the problem is posed is dynamic, new goals crop up that lead to new solution criteria, which, in turn, require new operators to reduce the distance between the initial and the goal state. With regard to this point, the contribution of situated cognition is not clear. The preceding analyses of situated cognition could improve the delimitation of problems or, perhaps, could force cognitive psychology to develop more complex theories to account for problem-solving strategies when problems are ill defined or when problems become more complex in the course of their solution. Situated cognition does not seem to have contributed anything of relevance in these three cases.
Second, Greeno (1998) mentions the problem of constructing meaning. According to this author, most studies carried out in cognitive psychology in this area refer to text comprehension, where reading activities are performed in a stable environment, but real life comprehension processes are performed in dynamic settings where meaning is the result of a negotiation strongly determined by the context. Although Greeno himself acknowledges the possibility of performing cognitive analyses of this type of problems along the lines of what has been done, however, he cautions about the need for more complex analyses "especially when the relevant context is constructed dynamically in conversations that are taking place and in problematic aspects of activity" (p. 5). Once again, while we agree about the complexity of the problem of constructing meaning, we do not see how situated cognition contributes to its solution.

Third, Greeno (1998) refers to the question of people's goals when they are generated in the course of activities and how they contribute to group functioning. This is certainly a very important problem and its consideration may add to the progress of motivational theories. However, from our perspective, the relation between this type of problems and a learning theory is rather distant. Again, this kind of vindication of situated cognition may be fruitful to analyze educational problems, but it involves the risk of mistaking a learning theory for a motivational theory. In fact, as mentioned, it is not clear that situated cognition has contributed to the solution of the problem of the meaning of teaching, for which it is supposedly prepared. Situated cognition should probably approach this problem more in detail and abandon, at least for the time being, its ambition to become an alternative to psychological learning theories.

To conclude, one could say that only when situated cognition carries its viewpoints to an extreme can it provide alternative explanations to those of psychology. The trouble with these explanations is that they have no scientific foundation and, in the majority of cases, are completely contrary to the available data. It is precisely this lack of scientific foundation that allows it to collide with psychology. In contrast, when situated cognition adopts more moderate viewpoints, it is difficult to know what it really contributes to the explanations of learning provided by psychology that was not already known even before this type of analysis proceeding from situated cognition appeared.

\section{References}

Agre, P.E., \& Chapman, D. (1987). Pengi: An implementation of a theory of activity. Proceedings of the Sixth National Conference on Artificial Intelligence (pp. 268-272). Menlo

Park, CA: American Association for Artificial Intelligence. Anderson, J.R. (1976). Language memory and thought. Hillsdale, NJ: Erlbaum. 
Anderson, J. R. (1983). The architecture of cognition. Cambridge, MA: Harvard University Press.

Anderson, J.R. (1990). The adaptive character of thought. Hillsdale, NJ: Erlbaum.

Anderson, J.R. (1991). Is human cognition adaptive? Behavioral and Brain Sciences, 14, 471-317.

Anderson, J.R., Reder, L., \& Simon, H.A. (1996). Situated learning and education. Educational Researcher, 25, 5-11.

Anderson, J.R., Reder, L., \& Simon, H.A. (1997). Situative and cognitive perspectives: Form versus substance. Educational Researcher, 26, 18-21.

Aparicio, J.J. (1986). El marxismo y la construcción de teorías en psicología. In R. Reyes (Ed.), Cien años después de Marx. (pp. 618-622). Madrid: Akal.

Aparicio, J.J. (1991). Los modelos animales en los actuales estudios sobre el aprendizaje humano. Psicothema, 3, 59-72.

Aparicio, J.J., \& Rodríguez Moneo, M. (2000). Los estudios de cambio conceptual y las aportaciones de la psicología del aprendizaje. Tarbiya: Revista de Investigación e Innovación Educativa, 26, 13-30.

Baddeley, A.D. (1976). The psychology of memory. New York: Basic Books.

Bickhard, M.H. (1992). How does the environment affect the person? In L. T. Winegar \& J. Valsiner (Eds.), Children's development in social context (pp. 63-92). Hillsdale, NJ: Erlbaum.

Brooks, R.A. (1991). New approaches to robotics. Science, 253, 1227-1232.

Brown, J.S., Collins, A., \& Duguid, P. (1989). Situated cognition and the culture of learning. Educational Researcher, 18, 32-42.

Carraher, T.N., Carraher, D.W., \& Schlieman, A.D. (1985). Mathematics in streets and in schools. British Journal of Developmental Psychology. 3, 21-9.

Ceci, S.J., \& Roazzi, A. (1994). The effects of contexts on cognition: Postcards from Brazil. In R.J. Stemberg \& R.K. Wagner (Eds.), Mind in context: Interactionist perspectives on human intelligence (pp. 74-101) Cambridge, MA: Cambridge University Press.

Clancey, W.J. (1992). The frame of reference problem in the design of intelligent machines. In K. VanLehn (Ed.), Architectures for intelligence (pp. 357-424). Hillsdale, NJ: Erlbaum.

Comber, L. C. \& Keeves, J. P. (1973). Science education in nineteen countries. New York: Wiley.

Dewey, J. (1896). The reflex arc concept in psychology. The Psychological Review, 3, 357-370.

Dewey, J. (1929). Experience and nature. New York: W. W. Norton.

Dewey, J. (1942). How is mind to be known. The Journal of Philosophy, 39, 29-72.

Dewey, J., \& Bentley, A. (1949). Knowing and the known. Boston, MA: Beacon Press.

Druckman, D., \& Bjork, R.A. (Eds.). (1994). Learning, remembering, believing: Enhancing team and individual performance. Washington, DC: National Academy Press.

Frege, G. (1892). Über Sinn und Bedeutung. Zeitschrift für Philosophie und philosophische Kritik, 100, 25-50. Translated as 'On Sense and Reference' by M. Black in Translations from the Philosophical Writings of Gottlob Frege, P. Geach and M. Black (eds. and trans.), Oxford: Blackwell, third edition, 1980.

Gentner, D. (1989). The mechanisms of analogical learning. In S. Vosniadou \& A. Ortony (Eds.), Similarity and analogical reasoning (pp. 199-241). London: Cambridge University Press.

Gibson, J. J. (1979). The Ecological Approach to Visual Perception. Boston: Houghton Miflin.

Greeno, J.G. (1997). On claims that answer the wrong questions. Educational Researcher, 26, 5-17.

Greeno, J.G. (1998). The situativity of knowing, learning and research. American Psychologist, 53, 5-26.

Harman, G. (1989). Some philosophical issues in cognitive science: Qualia, intentionality, and the mind body problem. In M. I. Posner (Ed.), Foundations of Cognitive Science. Cambridge. MA.: The MIT Press.

Hmelo, C.E., \& Narayan, N.H. (1995, July). Anchors, cases, problems, and scenarios as contexts for learning. In J.D. Moore \& J.F. Lehman (Eds.), Proceedings of the Seventeenth Annual Conference of the Cognitive Science Society (pp. 5-8). Mahwah, NJ: Erlbaum.

Holland, J.H., Holyoak, K.J., Nisbett, R.E., \& Thagard, P.R. (1986). Induction: Processes of inference, learning, and discovery. Cambridge, MA: MIT Press.

Holyoak, K.J. (1985). The pragmatics of analogical transfer. In G.H. Bower (Ed.), The psychology of learning and motivation (pp. 59-87). New York: Academic Press.

Johnson-Laird, P.N. (1983). Mental models. Cambridge, MA: Harvard University Press.

Kieras, D.E., \& Bovair, S. (1986). The acquisition of procedures from text: A production system analysis of transfer of training. Journal of Memory and Language, 25, 507-524.

Kieras, D.E., \& Polson, P.G. (1985). An approach to the formal analysis of user complexity. International Journal of ManMachine Studies, 4, 399-424.

Kintsch, W. (1977). Memory and cognition. New York: Wiley.

Lave, J. (1977). Tailor-made experiments and evaluating the intellectual consequences of apprenticeship training. The Quarterly Newsletter of the Institute for Comparative Human Development, 1, 1-3.

Lave, J. (1988). Cognition in practice. Cambridge, UK: Cambridge University Press.

Lave, J., \& Wenger, E. (1991). Situated learning: Legitimate peripheral participation. Cambridge, UK: Cambridge University Press.

Leontiev, A. N. (1978). Activity, consciousness, and personality. Englewood Cliffs: Prentice Hall.

Lowe, C. F. (1983). Radical behaviorism and human psychology. In G. Davey (Ed.), Animal models of human behavior (pp. 7194). New York: Wiley.

Luria, A. R. (1976). Cognitive development. Cambridge: Harvard University Press.

Malinowski, B. (1961). Argonauts of the western Pacific. New York: Dutton. (Original work published 1922)

Marr, D. (1982). Vision: A computational investigation into the human representation and processing of visual information. San Francisco: Freeman. 
Mead, M. (1928). Coming of age in Samoa. New York: Morrow.

Mitchell, T.M. (1982). Generalization as search. Artificial Intelligence, 18, 203-226.

Mitchell, T.M. (1983). Learning and problem solving. Proceedings of the Eighth International Joint Conference on Artificial Intelligence. Los Altos, CA: Kaufmann.

Nelson, T.O. (1976). Reinforcement and human memory. In W.K. Estes (Ed.), Handbook of learning and cognitive processes (Vol 3, pp. 207-246). Hillsdale, NJ: Erlbaum.

Newell, A. (1973). Production systems: Models of control structures. En W. G. Chase (Ed.), Visual Information Processing (pp. 466-526). New York: Academic Press.

Newell, A. (1980). Physical symbol systems. Cognitive Science, 4, 135-183.

Newell, A., Rosenbloom, P.S., \& Laird, J.E. (1989). Symbolic architectures for cognition. In M.I. Posner (Ed.), Foundations of cognitive science (pp. 93-131). Cambridge, MA: MIT Press.

Newell, A. \& Simon, H. A. (1972). Human problem solving. Englewood Cliffs, NJ: LEA.

Pascual-Leone, J. (1980). Constructive problems for constructive theories: The current relevance of Piaget's work and a critique of information processing simulation psychology. In R.H. Kluwe \& H. Spada (Eds.), Developmental models of thinking (pp. 263-296). New York: Academic Press.

Piaget, J. (1970). Genetic epistemology. (E. Duckworth, Trans.). New York : Columbia University Press.

Piaget, J. (1971). Psychology and epistemology. (A. Rosin, Trans.). New York : Grossman. (Original work published 1970.)

Pylyshyn, Z.W. (1980). The "causal power" of machines. The Behavioral and Brain Sciences, 3, 442-444.

Rodríguez Moneo, M. (1999). Conocimiento previo y cambio conceptual. Buenos Aires: Aike.

Rogoff, B., \& Lave, J. (Eds.). (1984). Everyday cognition: Its development in social context. Cambridge, MA: Harvard University Press.

Rosembloom, P.S., \& Newell, A. (1986). The chunking of goal hierarchies: A generalized model of practice. In R.S. Michalski, J.G. Carbonell, \& T.M. Mitchell (Eds.), Machine learning: An artificial intelligence approach (Vol. 2, pp. 247-288). Los Altos, CA: Kaufmann.
Ryle, G. (1949). Concept of the mind. London: Hutchinson.

Searle, J. (1980). Minds, brains, and programs. The behavioral and brain sciences, 3, 417-457.

Searle, J. (1983). Intentionality: An essay in the philosophy of mind. Cambridge, UK: Cambridge University Press.

Searle, J. (1984). Minds, brains and science. Cambridge, MA: Harvard University Press.

Seel, N.M. (2001). Epistemology, situated cognition, and mental models: "Like a bridge over troubled water." Instructional Science, 29, 403-427.

Singley, M.K., \& Anderson, J.R. (1985). The transfer of text editing skill. International Journal of Man-Machine Studies, 22, 403423.

Singley, M.K., \& Anderson, J.R. (1989). The transfer of cognitive skill. Cambridge, MA: Harvard University Press.

Skinner, B. F. (1974). About behaviorism. London: Jonathan Cape.

Skinner, B. F. (1984). Coming to terms with private events. Behavioral and Brain Sciences, 7, 572-581.

Slavin, R.E. (1995). Cooperative learning: Theory, research, and practice ( $2^{\text {nd }}$ ed.). Boston: Allyn \& Bacon.

Steffe, L.P., \& Gale, J. (1995). A constructivist approach to teaching. In L. P. Steffe \& J. Gale (Eds.), Constructivism in education (pp. 489-523). Hillsdale, NJ: Erlbaum.

Suchman, L.A. (1987). Plans and situated action: The problem of human-machine communication. New York: Cambridge University Press.

VanLehn, K. (1989). Problem solving and cognitive skill acquisition. In M. I. Posner (Ed.), Foundations of Cognitive Science (pp. 527-579). Cambridge, MA: MIT Press.

Vera, A.H., \& Simon, H.A. (1993). Situated action: A symbolic interpretation. Cognitive Science, 17, 7-48.

Vigotski, L.S. (1962). Thought and language. New York: Wiley. (Original work published 1934.)

Vigotski, L.S. (1978). Mind in society: The development of higher psychological processes. Cambridge, MA: Harvard University Press.

Received January 24, 2005 Revision received May 10, 2005 Accepted May 25, 2005 